\title{
Managing the Life Cycle to Reduce Environmental Impacts
}

\author{
Tiina Pajula, Katri Behm, Saija Vatanen and Elina Saarivuori
}

\begin{abstract}
Driven by public awareness and international regulations and standards, sustainability and environmental impacts have become increasingly important distinguishing factors between competing products and services. Circular economy aims to increase economic growth by using natural resources and ecosystems in a more effective way with the aim of maintaining products, components and materials at their highest utility and value at all times. More effective use of materials enables the creation of more value both by cost savings and by developing new markets or by developing existing ones. Reduced acquisition of resources is a driver for innovation for sustainable use of materials, components and products as well as new business models. This chapter introduces methods and tools to assess and reduce environmental impacts, and improve resource efficiency and sustainability management. Life cycle thinking forms one of the basic principles of sustainable development, and Life Cycle Assessment (LCA) is the leading method for assessing the potential environmental impacts of a product, process or service throughout its life cycle (ISO 14040-44). Other methods based on life cycle thinking are also introduced. LCA focusing on the contribution of a product or service to global warming uses methods for Carbon Footprint measurement and facilitates the tracking of greenhouse gas (GHG) emissions (ISO 14067). Water footprint is a tool that assesses the magnitude of potential water-specific environmental impacts of water use associated with a product, process or organisation. It aims at describing the impact of water utilization on humans and ecosystems due to changes in water quality and quantity (ISO 14046 Environmental managementWater footprint-Principles, requirements and guidelines 2014). The concept of
\end{abstract}

T. Pajula $(\bowtie) \cdot$ K. Behm $\cdot$ S. Vatanen $\cdot$ E. Saarivuori

VTT Technical Research Centre of Finland Ltd., Espoo, Finland

e-mail: tiina.pajula@vtt.fi

K. Behm

e-mail: katri.behm@vtt.fi

S. Vatanen

e-mail: saija.vatanen@vtt.fi

E. Saarivuori

e-mail: elina.saarivuori@vtt.fi

(C) The Author(s) 2017

S.N. Grösser et al. (eds.), Dynamics of Long-Life Assets,

DOI 10.1007/978-3-319-45438-2_6 
handprint has recently been introduced to measure and communicate the positive changes of actions and the beneficial impacts created within the life cycle of products, services, processes, companies, organizations or individuals. A handprint of a product can be created either by preventing or avoiding negative impacts (footprints), or by creating positive benefits. When adopting the circular economy way of thinking, companies need these tools and methods to ensure resource efficiency, cost cuts and improvements in their environmental performance which provide them with more earning opportunities. Fundamental changes throughout the value chain, from product design and production processes to new business models and consumption patterns, support this trend.

Keywords Life cycle assessment - Carbon footprint - Water footprint - Carbon handprint $\cdot$ Sustainability

\section{Introduction}

The interaction between industry and the natural environment is strong. The climate change and other environmental impacts related to industrial manufacturing have been discussed and agreed very widely during recent decades, which has increased pressure on industrial businesses (Lieder and Rashid 2016). Scientific understanding of the climate system and its sensitivity to greenhouse gas (GHG) emissions is nowadays more comprehensive than ever before. In December 2015, 195 countries and the European Union reached a global climate deal, agreeing to a long-term goal of limiting the increase in global average temperature to well below $2{ }^{\circ} \mathrm{C}$, which means that countries need to scale up their efforts and actions to reduce emissions (European Commission 2016). This will bring great challenges for industries of different sectors, such as those considered in the Use-It-Wisely (UIW) project (turbines, machinery, space, trucks, shipping and furniture). The existence of environmental regulations has been a considerable influence on some of these companies.

In addition to the environmental considerations, the companies also face another challenge, since resources are becoming scarcer and the competition for their acquisition harder (Lieder and Rashid 2016). Earth Overshoot Day is the annual marker of when we begin living beyond our means in a given year (Global footprint network 2015, www.overshootday.org). Although only an approximate estimate of time and resource trends, Earth Overshoot Day is as close as science can get to measuring the gap between our demand for ecological resources and services, and how much the planet can provide. Our demand for renewable ecological resources and the services they provide is now equivalent to that of more than 1.5 Earths. The unsustainable use of resources brings challenges to resource supply and price, since the increasing requirements for resources cannot be met everywhere (Lieder and Rashid 2016). The changing markets require quick responses from the industry, requiring green growth and a resource-efficient economy. 
Environmental topics have a direct effect on humans, but industry is also closely related to social aspects via employment and customer experiences related to the industrial products. Economic competence and growth bring new jobs to the market and thus create well-being, and satisfying customer experiences boosts the demand for products. Thus these three components-economic, environmental and social aspects of sustainability - create a positive circle supporting one another and can all be interlinked, managed and measured with a toolkit of various sustainability indicators.

The UIW-project aims to find solutions enabling rapid response to changing markets, business environments and customer needs. Sustainability methods and indicators presented in this article can help companies to achieve these goals by providing tools for managing and improving the sustainability performance of the manufacturing industry and its products. They can be used in finding new and improved business opportunities by e.g. increasing the efficiency of practices, and reducing waste streams both in the companies' own processes and elsewhere in the value chain. They can be applied in any industrial sector and for products as well as for services.

The methods presented in this chapter are based on life cycle thinking. It is a prerequisite to understand "the bigger picture", i.e. all the requirements and impacts that relate to the value chain of a product. Life cycle assessment (LCA) considers all materials and energy aspects during the entire supply chain, including raw material and fuel acquisition, different manufacturing and conversion processes, the use and consumption of the product and finally recycling or disposal. Together with life cycle thinking, circular economy emphasizes the sustainable use of resources by reducing, reusing and recycling materials and energy as much as possible (Yuan et al. 2006). Life cycle thinking and circular economy are presented in Sect. 2. These approaches ensure minimization of the overall environmental impacts and help avoid shifting the potential burden between different life cycle stages or individual production units or material and energy.

Section 3 introduces LCA, which is a method for assessing the environmental impacts created during the life cycle of a product. LCA can be used for identifying opportunities to improve the environmental performance of products; informing customers, stakeholders and other interest groups of environmental impacts from different stages of the life cycle; and marketing purposes in the forms of e.g. eco-labelling or environmental product declaration (EPD) (Tukker 2000). Section 4 describes other assessment methods that are based on life cycle thinking. The carbon footprint presented in Sect. 4.1 reflects the impact on climate change during the life cycle of a product. It typically describes the global warming potential within the next 100 years (BSI PAS2050:2011). Water footprint, presented in Sect. 4.2, is a measure of the magnitude of potential, water-specific environmental impacts of water use associated with a product, process or organisation, including both water quality and quantity aspects (ISO 14046 2014). Handprint, presented in Sect. 4.3, is a new concept that focuses on benefits rather than on negative impacts. The positive impacts can occur in the company's own actions or e.g. reduce the customer's footprint via improved product qualities (Shine 2015). Finally, the conclusions are presented in Sect. 5 . 


\section{Life Cycle Thinking and Circular Economy}

The basic understanding of life cycle methods is that all products and services have a value chain connected to them, that nothing in this world "stands alone", and that all our actions have consequences. Life cycle thinking considers all materials, fuels, energy and water consumed and the possible by-products, emissions and waste created when making, using and/or disposing a specific product. The life cycle begins from raw material extraction and conversion and continues via manufacturing and distribution to use and/or consumption. The life cycle ends with the so-called end-of life stage, including re-use, recycling of materials and energy recovery and/or disposal. In all these life cycle stages, the actions are connected to consequences, e.g. the materials used must be supplied from somewhere, with some energy demand and release of emissions. Resources are consumed and impacts to the environment are created within the life cycle of every product.

The core of life cycle thinking is to avoid shifting the environmental burden (European Commission 2010). This means that minimising impacts at one stage of the life cycle or in one environmental impact category should not cause increasing impacts elsewhere. Very often the value chains are international and the impacts e.g. on climate change have an effect on a global level. For example, saving energy during the use stage might increase the amount of material needed in manufacturing, or increase the energy needed in disposal of a product. Life cycle thinking aims to avoid these kinds of consequences.

The circular economy is based on sustainable use of resources. In a circular economy, the value of products and materials is maintained for as long as possible; waste and resource use are minimised, and resources are kept within the economy when a product has reached the end of its life, to be used again and again to create further value. The " $3 \mathrm{R}$ " principles - reduce, reuse, and recycle materials and energy - describe different possibilities to practice circular economy (Yuan et al. 2006).

Traditional economic systems tend to be based on a linear "take-make-dispose" production model (Sitra 2015). Products and production are based only on the initial use of the product and recycling is segregated from production. For the circular economy, however, there is a difference between the consumption and use of materials. Consumed materials become waste, but the circular economy aims to reduce waste through the efficient use of materials and other resources. Waste is prevented if products and services were designed for reuse, remanufacture or recycling as secondary materials. The goal is to retain the maximum possible value, related to production and the used materials, within the circular economy (Sitra 2015).

The circulation of products and raw materials can be promoted in the following ways (Sitra 2015):

1. Maintain: Build products to last longer without repairs and offer maintenance services to prolong product life cycles, enabling longer use by the same owner.

2. Reuse/redistribute: Reuse the product for the same purpose on the resale markets. 
3. Remanufacture: Plan the product life cycle as several life cycles and resell the product after thorough remanufacture.

4. Recycle: Recycle product materials for reuse and design products so that their materials are easy to sort. For biological materials, it would also be important to consider how to ensure the safe and sustainable return of nutrients to the nutrient cycle following their optimal use.

5. Cascade: Make use of a material or parts of it in another value chain, when it can no longer be used in the original sector.

The following conceptual diagram (Fig. 1) illustrates in a simplified way the main phases of a circular economy model. The phases are interlinked, as materials can be used in a cascading way, for example when industry exchanges by-products, products are refurbished or remanufactured, or consumers choose product-service systems. The aim is to minimise the resources escaping from the circle so that the system functions in an optimal way (European Commission 2014).

The circular economy seeks to make more efficient use of resources and materials, for the better recycling of their value and raw materials. Reuse and remanufacturing are good examples of the circular economy, since they save much of the energy used in the original production, such as in extraction of resources and further processing.

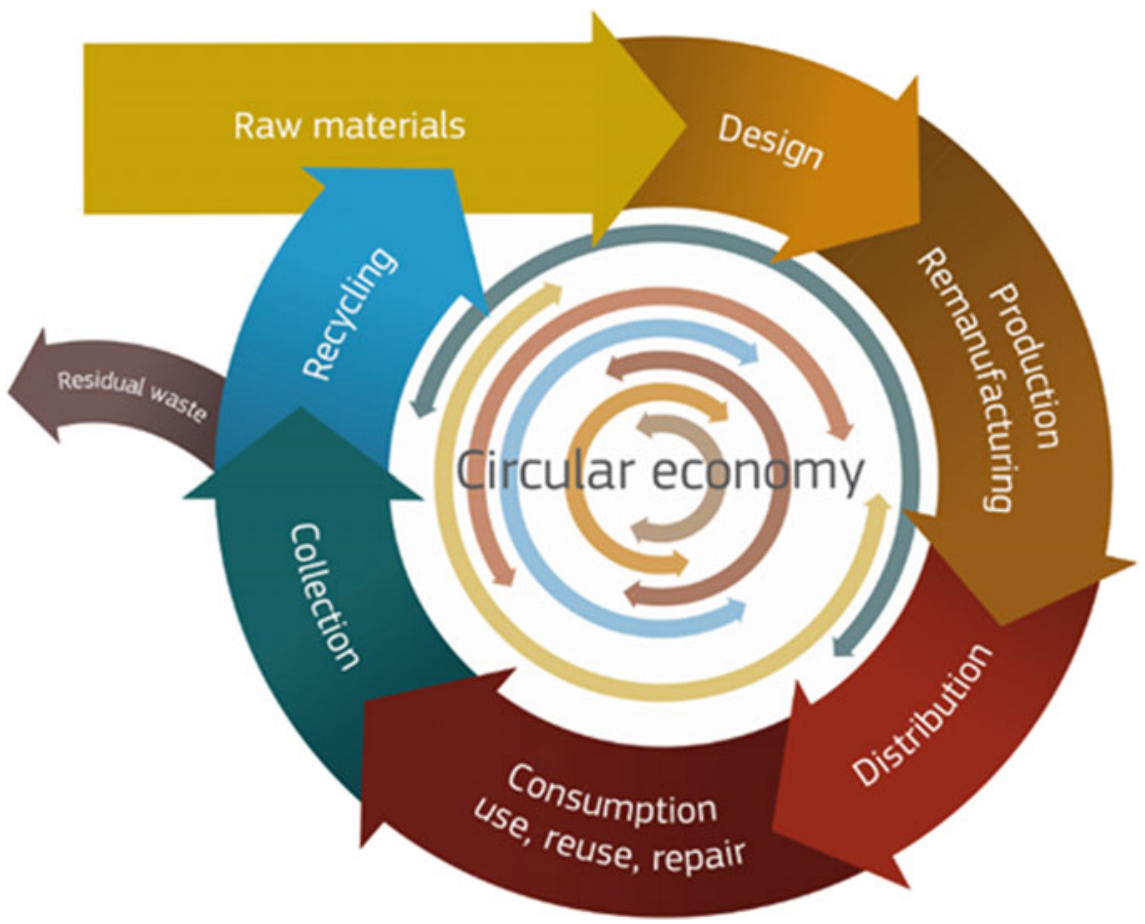

Fig. 1 Circular economy and life cycle phases (European Commission 2014) 
For companies, adopting the circular economy way of thinking would create opportunities to cut costs, grow their businesses and reposition themselves strategically (Sitra 2015). Resource and energy efficiency are precisely the areas where cost savings are most often achieved. Correspondingly, the circular economy provides companies with more earning opportunities for each manufactured product. However, this requires fundamental changes throughout the value chain, from product design and production processes to new business models and consumption patterns (EEA 2/2016). Whereas the order of magnitude of expected benefits of a transition to a circular economy is reasonably well known, the exact numbers in existing studies need to be treated with some caution, owing to methodological and data limitations. Furthermore, benefits will not be evenly distributed: some industrial sectors, businesses, regions and societal groups are likely to lose, while others will benefit. Chapter Sustainable Furniture that Grows with End-Users introduces how Gispen, a major office furniture producer in the Netherlands, has embraced circular economy principles to create new business, extend product life time and improve the adaptability of their products.

\section{Life Cycle Assessment}

The standards of LCA are ISO 14040:2006 "Environmental management-Life cycle assessment-Principles and framework" and ISO 14044:2006 "Environmental management-Life cycle assessment-Requirements and guidelines" (ISO 14040:2006; ISO 14044:2006). LCA can be used for identifying opportunities to improve environmental performance of products; informing customers, stakeholders and other interest groups of environmental impacts from different stages of a product's life cycle; and marketing purposes in the forms of e.g. eco-labelling or environmental product declaration (EPD) (Tukker 2000). LCA makes it possible to reveal mitigation points and critical phases along the supply chain of a product, process or a service and can also assist in strategic risk management, facilitate resource efficiency and optimization of environmental management as well as be a communication tool.

LCA has four stages (ISO 14040:2006; ISO 14044:2006). The first stage is Goal and scope definition. This defines the goal of the study, sets the system boundaries and lists the assumptions needed in the calculation. The second stage, called the life cycle inventory (LCI), includes data collection of input/output data and a balance calculation to all unit processes (the smallest element considered for which input and output data are quantified) in the life cycle. The results are presented as inputs and outputs of the entire system. The results from the inventory can be converted into impacts on the environment in the third stage, the life cycle impact assessment (LCIA). One example of this is the carbon footprint calculation; the emitted GHG from the inventory calculation are converted into global warming potentials in the impact assessment stage (ISO/TS 14067:2013). There are also several other impact categories, e.g. eutrophication, acidification and photochemical ozone formation. 
The final stage of LCA is interpretation of the results, which is based on all three previous stages of the assessment and summarises and discusses the conclusions and possible recommendations in accordance with the goal and scope definition. In some cases, the goal of the study can be fulfilled with just the LCI calculation and the interpretation, and the LCIA phase can be omitted. These studies should be called LCI studies and not LCA studies (ISO 14040:2006; ISO 14044:2006). The stages of the LCA are presented in Fig. 2.

When calculating LCA, the life cycle is modelled from unit processes which are connected to each other with material or energy flows (ISO 14040:2006). Each process has inputs and outputs which are connected to previous and subsequent processes from the beginning until the end of the product life cycle.

LCA results are sensitive for the chosen system boundaries and assumptions. One of the most important issues is definition of the system boundaries, i.e. the determination of stages of the product's life cycle that are included in the assessment (Pajula 2014). Full LCA is calculated from "cradle to grave" or "cradle to cradle". In addition to the linear part of the life cycle (production of raw materials and energy, manufacturing of the product, all transportations, use phase, and any disposal of the product or other end-of-life treatment) a "cradle to cradle" study includes recycling, reuse or remanufacturing. "Cradle to cradle" coverage is necessary when evaluating the concept of circular economy. "Cradle to gate" and "cradle to customer" calculations are partial LCAs considering the life cycle until the production of the product only (cradle to gate) or until the product has been transported to the customer (cradle to customer), but excluding the use phase and end-of-life steps. They are mainly used for business to business communication and as a starting point for more comprehensive LCAs.

There are two types of LCA approaches, which have different perspectives and thus can be used for different types of needs (Finnveden et al. 2009).

- Attributional LCA can be seen as a "conventional" approach that focuses on describing the environmentally relevant flows and impacts related to a product or process. It includes the full life cycle as it is, uses allocation (partitioning of the input or output flows of a process between the product system under study and one or more other product systems) and typically uses average data.

Fig. 2 The four stages of life cycle assessment

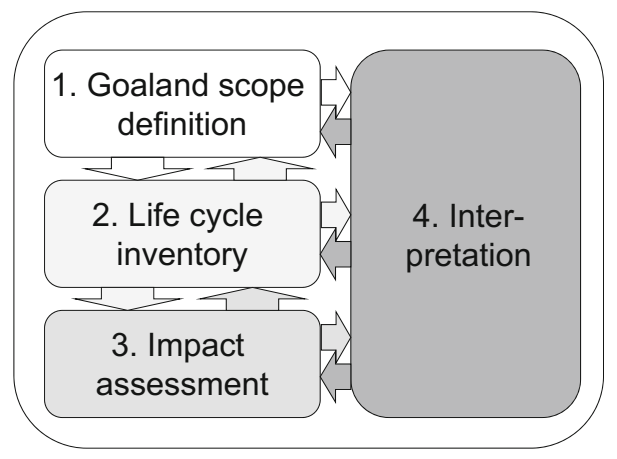


- Consequential LCA studies the change in environmental impacts related to a change in the life cycle. The result describes the consequences of actions within the life cycle, allocation is avoided through system expansion, and marginal data is used in the calculations. The selection between attributional and consequential approach should be made in the goal and scope definition phase depending on the purpose of the study.

The unit processes within the life cycle can be grouped according to the life cycle steps (e.g. energy production, transportation) or other coding (raw material supply, own processes, end-of-life), and the results can be studied transparently (ISO 14040:2006; ISO 14044:2006). Figure 3 shows an example of a life cycle, presenting the life cycle steps of a fibre product and the types of input and output flows related to each life cycle step.

Life cycle inventory (stage 2) calculations require vast amounts of highly specific data. The procedures related to LCI are shown in Fig. 4. Data can be collected from the production sites within the value chain, or it may be obtained from other sources, e.g. public databases. The LCA standards set specific requirements for e.g. time-related coverage, geographical coverage, technology coverage, precision, completeness and representativeness of the data. In addition, uncertainty and sensitivity of assumptions can be demonstrated via sensitivity analyses. The results of LCA are represented per functional unit, which describes the need that is fulfilled with the product or service. Typical functional units are numbers of product (e.g. one car or a book) or amounts of product (e.g. $1000 \mathrm{~kg}$ paper or 11 of diesel).

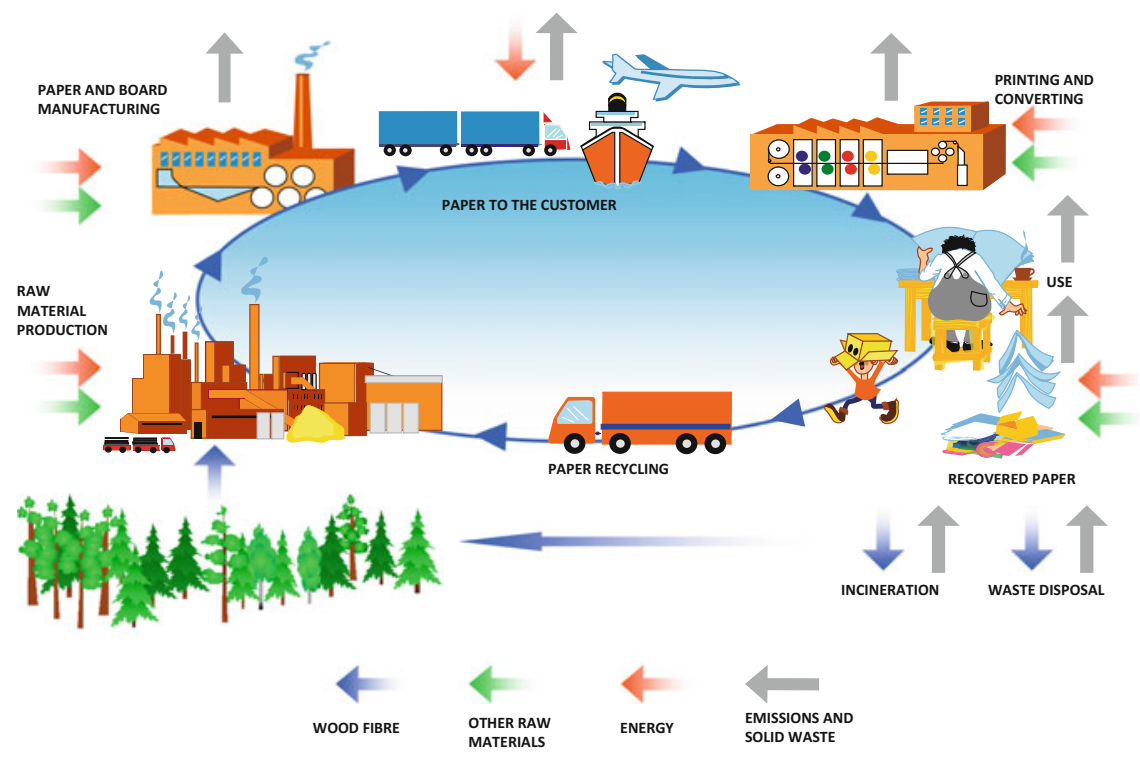

Fig. 3 Life cycle example of a fibre product 


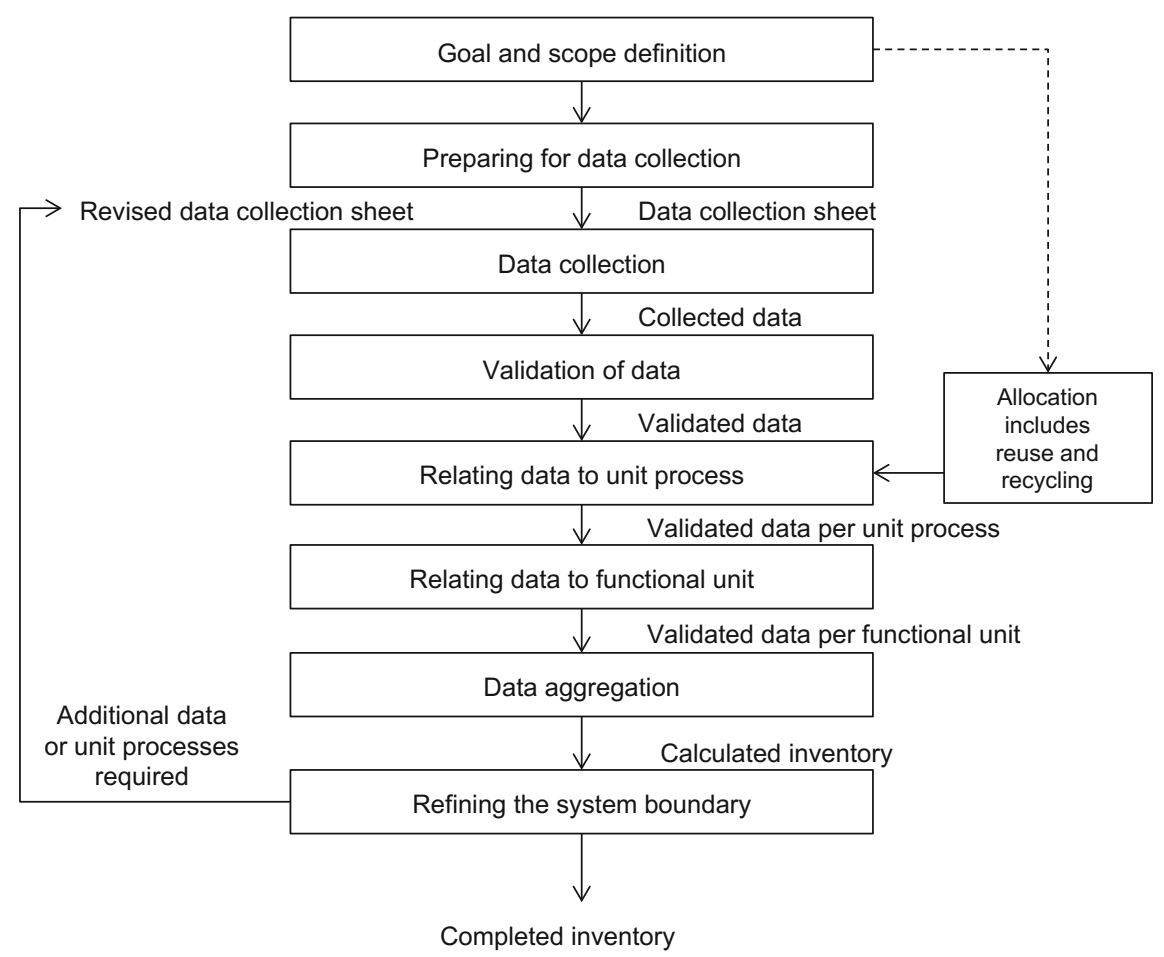

Fig. 4 The simplified procedures of life cycle inventory (ISO 14044)

Life cycle impact assessment (stage 3) consists of the following steps (ISO 14044:2006):

- Classification assigns the LCI results to one or more impact categories, e.g. $\mathrm{CO}_{2}$ influences global warming and $\mathrm{SO}_{2}$ can impact human health and acidification.

- Characterisation converts the LCI results into common units and aggregates the results within the same impact category. For example, $\mathrm{CH}_{4}$ and $\mathrm{N}_{2} \mathrm{O}$ are converted into $\mathrm{CO}_{2}$ equivalents with emission-specific factors (a global warming potential of $1 \mathrm{~kg} \mathrm{CH} \mathrm{CH}_{4}$ equals $25 \mathrm{~kg} \mathrm{CO} \mathrm{CO}_{2}$ eq.) and reported as $\mathrm{CO}_{2}$ equivalents.

- Normalisation calculates the magnitude of category indicator results relative to some reference information, which should be relevant considering the spatial and temporal scales of the study. The purpose is to better understand the relative magnitude for each indicator result of the product system studied. This step of impact assessment is optional, not mandatory.

- Grouping means that the impact categories are sorted and ranked. Grouping can be carried out either by sorting the impact categories on a nominal basis (e.g. by characteristics such as inputs and outputs) or by ranking the impact categories in 
a given hierarchy (e.g. high, medium and low priority). Ranking is based on value-choices and the results may be different when calculated by different parties. This step of impact assessment is also optional, not mandatory.

- Weighting converts and possibly aggregates indicator results across impact categories using numerical factors based on value-choices. Sensitivity analysis can be used to assess the consequences of value-choices. This step of impact assessment is again optional, not mandatory.

The steps of impact assessment are presented in Fig. 5.

The LCA standards do not determine which impact assessment methods should be used in a study. Selection of the method should be made in the goal and scope definition phase (stage 1), considering the spatial and temporal aspects of the study. Some methods include only characterisation factors but not normalisation or weighting factors, and these methods are called "the midpoint methods". For example, the CML 2001 impact assessment method can be mentioned as a midpoint method (CML 2001), and the ReCiPe method includes both midpoint and endpoint-indicators (ReCiPe 2013). According to Goedkoop et al. (2008), the midpoint indicators without weighting can be seen as more robust and less subjective than the endpoint indicators, but they might be difficult to compare or interpret due to their abstract meaning.

Environmental Product Declaration (EPD) is an LCA-based tool to communicate the environmental performance of a product. It is a document that communicates information about the life cycle environmental impact of products in a transparent and comparable way (ISO 14025 2006). To control the calculations and data collection, detailed requirements for some product group are developed; these are called Product Category Rules (PCR). For example there is a PCR for the assessment of the environmental performance of office furniture (EPD 2012).

"Critical review" is a specifically determined process for LCA that aims to ensure consistency between a LCA study and the guidelines of the ISO standard. This has to be used if the results of the study are to be published and used for a comparative assertion. Critical review can be carried out by an internal or external

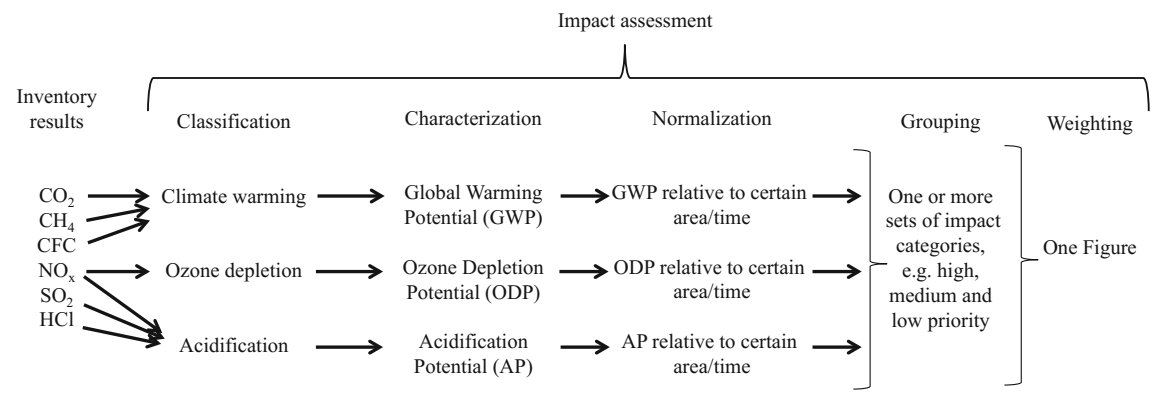

Fig. 5 Steps of impact assessment 
expert, who is independent of the LCA, or by a panel of interested parties. The review statement, comments of the expert and any responses to recommendations by the reviewer(s) must be included in the LCA report (ISO 14040:2006).

Since life cycle assessments are often rather extensive and the amounts of input/output data, flows and factors are very large, several calculation softwares have been developed to help the calculations. They often include generic databases and some impact assessment methodologies which are helpful in calculations. SimaPro, GaBi and SULCA can be mentioned as examples of LCA calculation tools (Loijos 2012; VTT 2014). Naturally, like every method, LCA has its limitations, for example, inclusion of biodiversity, littering, or animal well-being may be difficult in the calculations, due to lacking data and limitations in impact categories (Finkbeiner et al. 2014). Such challenges and limitations must be considered and recognized in the goal and scope definition phase when using the method.

\section{Other Methods Based on Life Cycle Thinking}

In addition to LCA, carbon and water footprint are currently the most commonly applied environmental assessment methods used by companies (Saurat et al. 2014). All three are based on life cycle thinking, but whereas LCA includes all environmental aspects, the others address specific environmental impacts such as climate change (carbon footprint) or water-specific environmental impacts (water footprint). As they were developed to study questions related to a certain specific environmental topic, it is important to be aware that carbon and water footprints cannot be used for an evaluation or communication of overall environmental superiority (ISO/TS 14067:2013; ISO 14046 2014). Extensive LCAs should be conducted first to identify the hotspots related to the production and value chains and to reveal the most critical environmental impacts. This then allows companies to focus later on the most important indicators, such as for example carbon footprint. This is possible especially for companies or sectors working with basically the same raw material, or mix of raw materials, from year to year, such as the aluminium or the forest industry (Saurat et al. 2014).

\subsection{Carbon Footprint}

Climate change caused by human actions has created a need to measure and mitigate GHG emissions. Carbon footprint is a concept that describes the GHG emissions and removals over the life cycle of a product expressed as $\mathrm{CO}_{2}$ equivalents (BSI PAS2050:2011). The quantification of a carbon footprint is based on the principles of LCA, focusing on the single impact category of climate change 
(ISO/TS 14067:2013). Benefits of carbon footprint as an indicator are that it easily understandable, globally interesting, broadly applicable and easy to implement for different strategies (Alvarez et al. 2016).

The carbon footprint of products standard (ISO/TS 14067:2013) provides principles, requirements and guidelines for the quantification and communication of the carbon footprint of products, including both goods and services. Calculations can also be made at an organisational level (ISO/TR 14069).

The $\mathrm{CO}_{2}$ equivalent of a specific amount of a GHG is calculated as the mass of a given GHG multiplied by its global warming potential factor given by the Intergovernmental Panel on Climate Change (IPCC). The factors describe the global warming potential of emissions over the next 100 years. The $\mathrm{CO}_{2}$ equivalents are then summed up and reported as carbon footprint. The factors for the most important GHG are reported in Table 1. The figures show that the impacts of different GHG on climate change vary so notably per physical unit that they cannot be directly compared and summed together at the inventory result level, but need to be converted into the impact assessment level instead (Fang and Heijungs 2015).

The typical sources of GHG emissions in carbon footprint calculations are energy production and consumption in the forms of electricity, heat or fuels, transportation and selection of raw materials. As in the LCA calculations, the results of footprint calculations can be divided into life cycle steps, and thus the most important emission sources are shown.

Carbon neutrality is a term that has been widely used in public discussion, although its meaning varies rather widely. It can be understood as zero fossil GHG emissions to the atmosphere, or as a situation in which the amount of released emissions is compensated by investing in projects that are mitigating GHG emissions elsewhere. Both perspectives have deficiencies, since the dynamics of biogenic carbon and land use change are very complex in the first approach, and the compensation does not remove the released emissions and their impacts from the atmosphere in the second approach. Thus the background and assumptions of carbon neutrality should always be reported in a high level of detail. The term "Offsetting" refers to compensating for all or for a part of the Carbon Footprint in a process outside the boundary of the product system through prevention, reduction or removal of GHG emissions, but it is not permitted in carbon footprint calculations (ISO/TS 14067 2013).

Table 1 Conversion factors of the most important greenhouse gases to carbon dioxide equivalents by IPCC (2007)

\begin{tabular}{l|c}
\hline & Conversion factor by IPCC \\
\hline Carbon dioxide, $\mathrm{CO}_{2}$ & 1 \\
\hline Methane, $\mathrm{CH}_{4}$ & 25 \\
\hline Dinitrogenmonoxide, $\mathrm{N}_{2} \mathrm{O}$ & 298 \\
\hline
\end{tabular}


Scientific communities and international guidance agree that all GHG emissions arising from fossil sources shall be included in Carbon Footprint calculations, whereas the inclusion of biogenic carbon involves more complexity and there are different views on its inclusion (Pajula 2014). Carbon sequestration in forests and storage in end products create carbon stocks for years, decades or even centuries and make biogenic carbon time-dependent, whereas fossil emissions can be considered to be released "today" (ISO/TS 14067 2013). On the other hand, although a sustainably managed biomass system is usually carbon neutral or even accumulates carbon over time, the timing difference between the release and sequestration of forest biomass carbon leads to a situation in which part of the carbon remains in the atmosphere until it is fully sequestered back into the growing forest. This leads to the fact that carbon neutral does not equal to climate neutral. The timing difference between emission and sequestration results first in a warming effect, whereas over a long period the accumulation of carbon results in a stock (Pajula 2014). Therefore, the conclusions of a study strongly depend on the forest management system in use and the timeframe chosen for the assessment (see Fig. 6, cf. Helin et al. 2012). The suitability of the different approaches presented in the literature for biomass carbon accounting within LCA was discussed by Helin et al. (2012). As there is no scientifically correct timeframe, it is recommended that different timeframes should be considered. Moreover, the technical specification requires reporting of biogenic emissions separately from fossil-based emissions (ISO/TS 14067 2013).

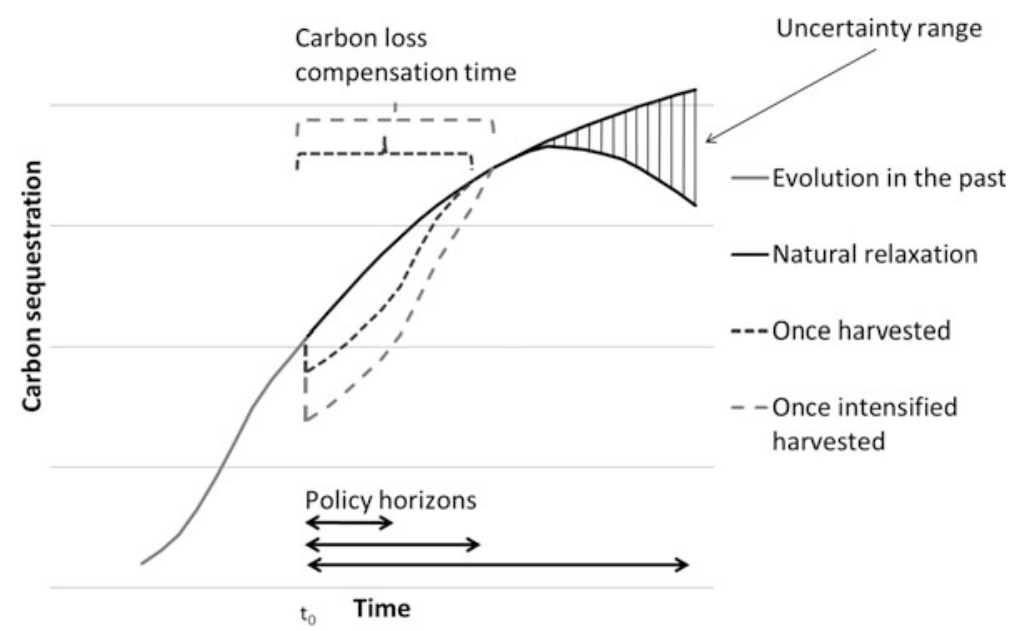

Fig. 6 A policy horizon considering climate impacts (Helin et al. 2012) 


\subsection{Water Footprint}

Water scarcity and the availability of fresh water is a global concern. Numerous industries have become vulnerable to water disruption. In recent years, there has been an increased interest to assess water-related impacts as a basis for improved water management at local, regional, national and global levels. At the company level, it is not only important to ensure a supply of water, control the emissions to water and maintain the local environment, but also to understand the indirect water and the risk factors that occur when operating in different regions. One of the methods developed for this purpose is water footprint.

Water footprint is a tool that assesses the magnitude of potential, water-specific environmental impacts of water use associated with a product, process or organisation. It aims at describing the impact of water use on humans and ecosystems due to changes in water quality and quantity, making it possible to reveal mitigation points along the supply chain. Compared to the product carbon footprint, which describes the global warming potential of a product with a global impact, the water footprint is a local indicator.

Various initiatives by different institutions and organisations have been launched in order to develop analytical tools to measure and assess freshwater use and water footprint (Hoekstra et al. 2011; Ridoutt and Pfister 2010). Due to a great variety of different methods, comparison of the results has been difficult. In order to harmonise the methodology and approach, the ISO Standard 14046 was launched in 2014. The standard provides principles, requirements and guidelines for water footprinting. A water footprint assessment conducted according to this standard is based on a LCA (ISO 14044 2006). An LCA-based water footprint is the fraction of impact assessment results which are related to water resources. Water footprint is a sum of the water footprint of different life cycle stages, identifies potential environmental impacts related to water, includes geographic and temporal dimensions, identifies quantity of water use and changes in water quality, and utilises hydrological knowledge. Because any change in water quality and in water quantity may have an impact on the availability or possible uses of water, it is important to consider both aspects in the impact assessment.

Although the standard sets principles for the water footprint assessment, specific methods or characterization factors that should be used for the assessment are not defined in the standard. Several methods have been developed proposing different inventory schemes and impact assessment models to account for the impacts associated with water consumption or water quality degradation. Different methods use different underlying assumptions, modelling choices, and conceptualisation of what actually constitutes an impact of water use (Boulay et al. 2015; Kounina et al. 2013). Impacts may include contributions to regional water scarcity, depriving other users of access to water, reducing the water flows required to maintain ecosystem functions, or degradation of water quality. No single method is available which comprehensively describes all potential impacts derived from fresh water use 
(Kounina et al. 2013). Currently, the WULCA group (Water Use in LCA, UNEP-SETAC Life Cycle Initiative) is coordinating a consensus-building process and leading the scientific work towards achieving a harmonised method to assess water use in LCA (WULCA 2015).

Water footprint can be presented as the result of a stand-alone assessment (in which only potential environmental impacts related to water are assessed) or is a sub-set of results of a larger environmental assessment (e.g. LCA, in which consideration is given to all relevant potential environmental impacts). According to the ISO standard, a qualifier is used if a water footprint study is limited to only certain aspects. A "water scarcity footprint" or "water availability footprint" assesses impacts associated with water use only, and "water eutrophication footprint" assesses the impact related to eutrophication only. If all relevant water use impacts are included (e.g. water use, eutrophication, acidification, freshwater toxicity), the study can be called water footprint (with no qualifier).

Water footprint and environmental risk assessment can be connected to derive complementary data on product water sustainability (Saarivuori et al. 2015). This provides companies with a way to manage and foresee water use related impacts and risks and can be used as a basis for a broader water disclosure, providing a deeper understanding of water risks for the companies themselves, the investors and other stakeholders. In addition, water footprint provides a scientific basis and a framework to assess water efficiency.

\subsection{Handprints}

The concept of handprint has been introduced rather recently (CEE 2007) to measure and communicate the positive changes of actions and the beneficial impacts, whereas the footprint measures the negative impacts in terms of emissions and resource consumption. Operating an organization always creates some kind of footprint, but it can also bring positive changes and benefits to the surrounding world. The estimate of those impacts of positive change is called a handprint (Norris 2015b).

The handprint concept can be applied to products, processes, companies, organizations or individuals, and it can consider the impacts on environment or society. Handprint evaluates the environmental impact of the object of study in two categories: the delivered benefit and the good the object of study does. Handprint builds on the concept of environmental footprint and the concept is characterized by unlimited potential and a self-reinforcing positive feedback loop (Biemer et al. 2013a, b). This means the handprint can sustain itself once it is established as companies tell others what they learned, and they in turn will tell others. The handprint and the footprint are not exclusive, but rather complementary ways of thinking. 
According to Norris (2015a), a handprint of a product can be created either by preventing or avoiding negative impacts (footprints) that would otherwise have occurred, or by creating positive benefits that would not have occurred. The handprint of a company considers the footprint of the company itself, but also the positive changes the company may have on individuals or other companies. This includes changes in the supply chain and also takes into account the changes which are indirectly associated with the goods and services the company produces. Handprints can take place anywhere in the world and they can be composed of multiple small impact reductions.

Handprinting includes three steps (SHINE 2015):

1. Measure and reduce company footprint (e.g. reduce emissions, promote eco-efficiency in supply chains and dematerialize goods and services).

2. Support others to reduce their footprints (e.g. promote innovations in the supply chain which reduce the footprints of goods and services sold to other companies, improve use phase efficiency, educate downstream customers to use products more effectively or efficiently, share innovations with other businesses and increase demand for own products with better performance (smaller footprint) than that of displaced products).

3. Take actions which address the same kind of impact categories on which footprints are causing negative impacts.

Both consequential (change-oriented and focused on the consequences of possible future changes between alternative product systems) and attributional (impacts of a specific product system based on an account of the history of the product) LCA can be applied in these assessments (Norris 2013).

Generating handprints is about actions that increase sustainability and well-being and reduce harmful activities and impacts in terms of both humans and the planet (SHINE 2015). The idea is to create and communicate positive changes in the whole supply chain from factories to customers. Handprints complement the footprint and bring similar quantitative and life cycle based assessment methods to address a much wider scope of action (global focus and multiple impact categories for companies to strive towards being net positive). Handprinting also highlights the positive approach to impact assessment that can motivate and inspire company staffs and promote creativity and new ideas on how to create more positive company impacts. Handprint covers a growing set of sustainability dimensions such as climate change, human health, biodiversity and water consumption. There is also a growing set of social performance indicators. However, better assessment tools and further definition of the handprint calculation method are needed if companies want to communicate the benefits achieved and their high level of clean-tech knowhow. 


\section{Conclusion}

The benefits of a transition towards a circular economy in Europe could be considerable, reducing environmental pressures in Europe and beyond and decreasing the continent's high and increasing dependence on imports (EEA 2/2016). Increasingly, this dependence could be a source of vulnerability. Growing global competition for natural resources has contributed to marked increases in price levels and volatility. Circular economy strategies could also result in considerable cost savings, increasing the competitiveness of Europe's industry while delivering net benefits in terms of job opportunities (EEA 2/2016).

Reduction of environmental impacts from industry can be obtained with effective life cycle management. Consideration of the full life cycle of products, i.e. life cycle thinking, is a prerequisite for full understanding of actions and their consequences, both in the industrial manufacturing phase and elsewhere in the life cycle. Sustainability indicators and tools can provide beneficial information for creating new business opportunities and innovation processes. They provide transparent information of resource and energy consumptions in different parts of the life cycle and also reveal the most important sources of emission and waste. Thus they can be of help in finding the most environmentally burdening processes and phases in the life cycle so that the correcting actions can be directed efficiently to those areas with the best improvement potentials. The life cycle management can also reduce the resource requirements and create more economic value by reducing, reusing and recycling of materials and energy while minimising the costs and the amount of waste created.

The methods listed in this article are focused on environmental impacts from the life cycles of products and services. Life cycle thinking, circular economy and LCA provide a starting point for companies to think, act and manage their production sustainably. Although still having some methodological challenges, such as the allocation of burden between products in recycling systems or inclusion of biogenic carbon, they are widely known and accepted approaches that have gained a permanent status as sustainability tools. They can be applied in all sectors, all products and all services in the world, globally and locally, and they can be used for existing processes or in the design and development phases of new products and processes. They provide information for internal use but also for communication and marketing purposes. The tools can bring benefits to the companies and industry sectors and increase the know-how of sustainability both at the producer and consumer level.

The carbon footprint and water footprint are nowadays standardized and accepted methods that are based on LCA. They focus on specific topics of climate change and water quality and scarcity, respectively. They can be useful when studying a specific product, industrial location or company, and they are rather easy to communicate and interpret. However, it is essential to keep in mind that environmental challenges are not limited to carbon or water, and optimizing a single indicator may cause trade-offs with other impacts. 
The concept of handprints on the other hand is still being developed. Handprints aim at communicating the benefits of actions, the positive impacts rather than the negative impacts measured by the footprints. Companies should follow the development process of handprints and provide feedback to the concept developers in order to reach the full benefits that can be created. The positive impacts and their communication as handprints can generate competitive advantage for companies, improve the brand and reputation and increase demand for the company's products.

As new circular approaches emerge, frictions between the existing linear system and the new approaches are bound to arise. These may be perceived as threats by some stakeholders, but as opportunities by others. The UIW-project considers six clusters, namely turbines, machinery, space, trucks, shipping and office furniture. They can all apply the life cycle management options reported in this article to support sustainable design of product services and production processes. Life cycle thinking, efficient use and recycling of materials, environmental impact assessment and consideration of positive actions can enhance new business opportunities, improve competitiveness and extend the life cycles of industrial products/services. Good practical examples exist. For example, businesses are already employing or experimenting with new business models such as service- and function-based business models and collaborative consumption. Governments increasingly foster waste prevention, reuse and repair (EEA 2/2016). At the same time more information is needed to inform decision making and combine thinking about environmental, social and economic impacts. Better insight is needed into production structures and functions, consumption dynamics, finance and fiscal mechanisms, as well as triggers and pathways for technological and social innovations.

\section{References}

Alvarez, S., Carballo-Penela, A., Mateo-Mantecón, I., \& Rubio, A. (2016). Strengths-weaknesses-opportunities-threats analysis of carbon footprint indicator and derived recommendations. Journal of Cleaner Production, 121(2016), 238-247. http://www. sciencedirect.com/science/article/pii/S0959652616001736. Accessed May 09, 2016.

Biemer, J., Dixon, W., \& Blackburn, N. (2013a). Our environmental handprint. The good we do. Institute of electrical and electronic engineers. Presented at the 2013 IEEE Conference on Technologies for Sustainability. http://handprint.in/Our_Envir_Handprint_IEEE_Paper_6-1413wc.pdf. Accessed December 10, 2015.

Biemer, J., Dixon, W., \& Blackburn, N. (2013b). Our environmental handprint. The good we do. In SusTech 2013, Portland Oregon. Conference presentation. http://sites.ieee.org/sustech/files/ 2013/12/QL1_BIEMER-Env_Handprint.pdf. Accessed December 10, 2015.

Boulay, A.-M., Motoshita, M., Pfister, S., Bulle, C., Muñoz, I., Franceschini, H., et al. (2015). Analysis of water use impact assessment methods (part A): Evaluation of modelling choices based on a quantitative comparison of scarcity and human health indicators. International Journal of Life Cycle Assessment, 20, 139-160. doi:10.1007/s11367-014-0814-2.

BSI PAS 2050:2011. (2011). Specification for the assessment of the life cycle greenhouse gas emissions of goods and services (Vol. 38). London, UK: British Standards Institution (BSI). ISBN 9780580713828 http://shop.bsigroup.com/upload/shop/download/pas/pas2050.pdf. Accessed March 15, 2016. 
CEE. (2007). The 4th International Conference on Environment Education. Ahmedabad, India: Centre for Environment Education (CEE). 24-28 November, 2007. http://www.ceeindia.org/ tbilisiplus30/. Accessed March 02, 2016.

CML. (2001). Impact assessment method.

EEA Report No 2/2016. Circular economy in Europe, developing the knowledge base.

EPD. (2012). PCR 2012:19. In Other furniture, of a kind used in offices and other furniture n.e.c. (Version 1.1). http://www.environdec.com/en/PCR/Detail/?Pcr=8458\&show_login= true\&new_user=true. Accessed May 30, 2016.

European Commission. (2010). Making sustainable consumption and production a reality. A guide for business and policy makers to life cycle thinking and assessment (Vol. 32). Luxembourg: Publications Office of the European Union. http://ec.europa.eu/environment/ pubs/pdf/sustainable.pdf. Accessed May 30, 2016.

European Commission. (2014). Communication from the commission to the European parliament, the council, the European economic and social committee and the committee of the regions. Towards a circular economy: A zero waste programme for Europe. In COM (2014) 398 final. 14.

European Commission. (2016). Climate action. Paris agreement. http://ec.europa.eu/clima/ policies/international/negotiations/paris/index_en.htm. Accessed May 30, 2016.

Fang, K., \& Heijungs, R. (2015). Investigating the inventory and characterization aspects of footprinting methods: Lessons for the classification and integration of footprints. Journal of Cleaner Production, 108(2015) part A, 1028-1036.

Finkbeiner, M., Ackermann, R., Bach, V., Berger, M., Brankatschk, G., Chang, Y.-J., et al. (2014). Challenges in life cycle assessment: An overview of current gaps and research needs. Background and future prospects in life cycle assessment (pp. 207-258). Berlin (DE): Springer.

Finnveden, G., Hauschild, M. Z., Ekvall, T., Guinée, J., Heijungs, R., Hellweg, S., et al. (2009). Recent developments in life cycle assessment. Journal of Environmental Management, 91(1), $1-21$.

GeSI. (2012). GeSI SMARTer 2020: The role of ICT in driving a sustainable future. In The Global e-Sustainability Initiative (GeSI). http://gesi.org/assets/js/lib/tinymce/jscripts/tiny_mce/plugins/ ajaxfilemanager/uploaded/SMARTer\%202020\%20-\%20The\%20Role\%20of\%20ICT\%20in\% 20Driving\%20a\%20Sustainable\%20Future\%20-\%20December\%202012.pdf. Accessed March 6, 2016.

Goedkoop, M. J., Heijungs, R., Huijbregts, M., De Schryver. A., Struijs, J., \& Van Zelm, R., ReCiPe. (2008). A life cycle impact assessment method which comprises harmonised category indicators at the midpoint and the endpoint level (1st ed.). In Report I: Characterisation. January 6, 2009. http://www.lcia-recipe.net. Accessed May 10, 2016.

Helin, T., Sokka, L., Soimakallio, S., Pingoud, K., \& Pajula, T. (2012). Approaches for inclusion of forest carbon cycle in life cycle assessment-A review. GCB Bioenergy, 5, 475-486. doi:10. 1111/gcbb.12016.

Hoekstra, A. Y., Chapagain, A. K., Aldaya, M. M., \& Mekonnen, M. M. (2011). The water footprint assessment manual: Setting the global standard. London, UK: Earthscan.

ISO 14025. (2006). Environmental labels and declarations-Type III environmental declarations -Principles and procedures.

ISO 14040. (2006). Environmental management, life cycle assessment, principles and framework.

ISO 14044. (2006). Environmental management, life cycle assessment, requirements and guidelines.

ISO 14046. (2014). Environmental management_Water footprint-Principles, requirements and guidelines.

ISO/TS 14067. (2013). Greenhouse gases. Carbon footprint of products. Requirements and guidelines for quantification and communication. 
IPCC. 2007: Climate Change (2007). The Physical Science Basis. In S. Solomon, D. Qin, M. Manning, Z. Chen, M. Marquis, K.B. Averyt, M. Tignor and H.L. Miller (Eds.), Contribution of Working Group I to the Fourth Assessment Report of the Intergovernmental Panel on Climate Change (996 pp)Cambridge, United Kingdom, New York, USA: Cambridge University Presshttp://www.ipcc.ch/pdf/assessment-report/ar4/wg1/ar4_wg1_full_report.pdf Accessed April 25, 2016.

Kounina, A., Margni, M., Bayart, J.-B., Boulay, A.-M., Berger, M., Bulle, C., et al. (2013). Review of methods addressing freshwater use in life cycle inventory and impact assessment. International Journal of Life Cycle Assessment, 18(3), 707-721.

Lieder, M., \& Rashid, A. (2016). Towards circular economy implementation: A comprehensive review in context of manufacturing industry. Journal of Cleaner Production, 115(2016), 3651.

Loijos, A. (2012). Comparison of best life cycle assessment software. http://www.linkcycle.com/ comparison-of-best-life-cycle-assessment-software/ (online document). Accessed April 27, 2016.

Norris, G. (2013). The new requirement for social leadership: Healing. In S. Groschl (Ed.), Uncertainty, diversity and the common good: Changing norms and new leadership paradigms. London: Gower Publishing. http://www.chgeharvard.org/sites/default/files/resources/ Introduction\%20to\%20Handprinting.pdf. Accessed November 24, 2015.

Norris, G. (2015a). Handprint-based netpositive assessment. Sustainability and Health Initiative for NetPositive Enterprise (SHINE), Center for Health and the Global Environment, Harvard T. H. Chan School of Public Health. http://www.chgeharvard.org/sites/default/files/resources/ Handprint-Based\%20NetPositive\%20Assessment.pdf. Accessed January 4, 2016.

Norris, G. (2015b). A one-page introduction to handprints. Sustainability and Health Initiative for NetPositive Enterprise (SHINE), Center for Health and the Global Environment, Harvard T.H. Chan School of Public Health. Accessed December 2, 2015.

Outotec. (2015). Maximizing our handprint-Outotec's sustainability report 2014. http://www. outotec.com/ImageVaultFiles/id_1598/cf_2/27729-Outotec_Sustainability_aukeemittain.PDF. Accessed December 21, 2015.

Pajula, T. (2014). Life cycle assessment of biobased materials. In Handbook of green materials (Vol. 5, Chapter 17). World Scientific.

ReCiPe. (2013). Methodology for life cycle impact assessment (LCIA).

Ridoutt, B. G., \& Pfister, S. (2010). A revised approach to water footprinting to make transparent the impacts of consumption and production on global freshwater scarcity. Global Environmental Change, 20, 113-120.

Saarivuori, E., Molarius, R., Wessman-Jääskeläinen, H., \& Poussa, L. (2015). Connecting water footprint and water risk assessment: Case packaging board. Water Practice \& Technology, 10 (1), 229-241.

Saurat, M., Ritthoff, M., Pihkola, H., Alonso, A., \& Lopez, A. (2015). Description of current industry practice and definition of the evaluation criteria. In EU SAMT, D2.1.

Shine. (2015). Shine summit 2015. Innovating for netpositive impact. Summary Report. Sustainability and Health Initiative for NetPositive Enterprise (SHINE), Center for Health and the Global Environment, Harvard T.H. Chan School of Public Health. http://chgeharvard. org/sites/default/files/resources/Shine\%20Paper\%202015\%20for\%20web-update.pdf. Accessed December 2, 2015.

Sitra. (2015). The opportunities of a circular economy for Finland. In Sitra studies 100 (72 pp). ISBN 978-951-563-938-7.

Tukker, A. (2000). Life cycle assessment as a tool in environmental impact assessment. Environmental Impact Assessment Review, 20(4), 435-456. 
VTT. (2014). SULCA-Sustainability tool for ecodesign, footprints \& LCA. SimulationStore, VTT Technical Research Centre of Finland LTD. https://www.simulationstore.com/sulca (online document). Accessed April 27, 2016.

WULCA. (2015). Consensual method development: Preliminary recommendation-AWaRe v1.1. In Water use in LCA (WULCA) working group. Accessible from: http://www.wulca-waterlca. org/. Accessed November 10, 2015.

Yuan, Z., Bi, J., \& Moriguichi, Y. (2006). The circular economy: A new development strategy in China. Journal of Industrial Ecology, 10(1-2), 4-8.

Open Access This chapter is licensed under the terms of the Creative Commons Attribution-NonCommercial 4.0 International License (http://creativecommons.org/licenses/by-nc/ 4.0/), which permits any noncommercial use, sharing, adaptation, distribution and reproduction in any medium or format, as long as you give appropriate credit to the original author(s) and the source, provide a link to the Creative Commons license and indicate if changes were made.

The images or other third party material in this chapter are included in the chapter's Creative Commons license, unless indicated otherwise in a credit line to the material. If material is not included in the chapter's Creative Commons license and your intended use is not permitted by statutory regulation or exceeds the permitted use, you will need to obtain permission directly from the copyright holder.

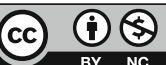

